\title{
Study on External Power Receiving Planning of Receiving-end Grid in AC/DC Hybrid Background
}

\author{
Liangdong Qin ${ }^{1}$, Jing Zhang ${ }^{2}$, Ying Wang ${ }^{2}$, Peng Xi ${ }^{2}$, Ning Wang ${ }^{2}$, Zhendong $\mathrm{Wan}^{3}$ and Shujing Yang,a \\ ${ }^{1}$ State Grid Hebei Electric Power CO., LTD, Grid development department, 050011 Hebei, China \\ ${ }^{2}$ State Grid Hebei Economic Research Institute, Grid planning research center, 050011 Hebei, China \\ ${ }^{3}$ East China Electric Power Design Institute, System planning research center, 200001 Shanghai, China
}

\begin{abstract}
Based on the practical experience of power grid planning, the general characteristics and main problems of the receiving-end grid are summarized, and the ideas and methods of external power receiving planning are put forward. Combined with the current situation, the pattern of power supply and demands of a typical recipient power network in China, this paper analysed the reasonable scale of power receiving, the proportion of $\mathrm{AC} / \mathrm{DC}$ power transmitted and the infeed $\mathrm{AC} / \mathrm{DC}$ terminal location for long-term development, and conducts comprehensive technical and economic comparisons among various feasible external power receiving schemes to form a recommended scheme.
\end{abstract}

\section{Introduction}

The inverse distribution of energy resources and load centers in China determines that the scale of crossregional transmission will continue to increase in the future. With the accelerated implementation of the action plan for the air pollution prevention and control, the power flow transmission scale of " West-East and NorthSouth Electricity Transmission Project" in China is increasing continuously. The power receiving proportion of the main load centers in the Central East is rising continuously. External electricity has gradually become an important part of the power security for the receivingend grid. Extra large-scale AC/DC system and multiinfeed HVDC system have gradually become the main features of the receiving-end grid in China ${ }^{[1-2]}$.

In order to guide the construction of power grid and ensure the security and stability of receiving-end grid, it is necessary to study and solve a key problem, which is how to scientifically plan the scheme of receiving power from outside the area. The problems that need to be studied include reasonable power receiving scale, transmission mode and receiving-end point scheme. These problems have gradually become the core issues of power grid planning in economically developed areas of China ${ }^{[3,4]}$. At present, there are few studies on the receiving-end power grid planning, and most of the related literatures focus on the mechanism and characteristics of external power as well as measures to improve the external power consumption capacity ${ }^{[5,6]}$. Liao Minchuan studied the analysis method of voltage stability at receiving-end grid of AC / DC hybrid system with UHVDC ${ }^{[7]}$. Lin Weifang studied the interaction characteristics of multiple HVDC from the perspective of short circuit ratio ${ }^{[8]}$. Chen Bo studied the static

\footnotetext{
a Corresponding author: yangsj3198@ecepdi.com
}

reactive voltage control and capacitive reactive power balance of Shanghai power grid under the background of AC-DC electric power from external regions [9]. Wang Weiyuan studied the influence of external power in high proportion area on auxiliary service of receiving-end power grid ${ }^{[10]}$. However, the above studies all focus on local problems in the receiving-end grid planning, fail to give overall consideration to all aspects of the external power receiving, fail to put forward the general ideas and principles of the external power receiving planning, and fail to integrate safety, economy, reliability, environmental adaptability and other considerations into the external power receiving planning.

Based on the practical experiences of power grid planning, the general characteristics and main problems of the receiving-end grid are summarized, and the ideas and methods of external power receiving are put forward. Combined with the current situation, the pattern of power supply and demands of a typical recipient power network in China, this paper analysed the reasonable scale of power receiving, the proportion of $\mathrm{AC} / \mathrm{DC}$ power transmitted and the infeed $\mathrm{AC} / \mathrm{DC}$ terminal location for long-term development, and conducts comprehensive technical and economic comparisons among various feasible external power receiving schemes to form a recommended scheme. The planning trains and methods presented in this paper will provide guidance and reference for regional backbone grid planning and receiving-end grid planning.

\section{Characteristics and Main Problems of Receiving-end Grid}

Receiving-end grid is a regional power grid centered on a centralized load area, including power plants in and 
near the area. Hub substations are connected with these power sources by a denser network to accept power and energy input from external and remote sources.

For many years, the recipient main grid in the central and eastern part of China has generally been planned and designed according to the way of power transmission which carries local power sources to be consumed locally, but the large-scale AC/DC power supply outside the region has not been taken into account. The main problems of the receiving-end power network include the following:

(1) Insufficient capacity of power evacuation and transfer in the vicinity of DC infeed terminal. On the one hand, the local absorption of UHVDC near the infeed terminal is far from expected. On the other hand, the over-expected growth of new energy installations in the area results in insufficient power transmission through the transmission channel.

(2) Frequency safety risk after loss of large capacity electrical channel. On the one hand, with the increasing capacity of a single power channel, the power network is facing the threat of a greater frequency impact source; on the other hand, with the increase of the power scale, the substitution effect of external power sources on the conventional power sources in the network is further aggravated, and the frequency characteristics of the power network are deteriorating.

(3) Insufficient voltage support capability of the receiving power network. Most existing DC transmission systems use thyristor converter valves. DC operation depends on the voltage support of AC system. Near-zone $\mathrm{DC}$ commutation failure is prone to occur when $\mathrm{AC}$ system fails.

(4) Short-circuit current control is difficult and expensive. In order to control short-circuit current, the operating Department has taken passive measures such as shutdown and line breaking, which all at the expense of network integrity, reliability and flexibility, thus causing cross-regional accident support, inter-provincial power balance, and clean energy absorption capacity to be affected and weakened to varying degrees.

(5) High peak-shaking pressure in power network. In response to the national policy to fully absorb clean hydropower energy and avoid and reduce the abandonment of clean energy at the transmission end, the current direct current for transmission of hydropower runs at full power for a long time during the summer flood season, which is severely limited by the output of conventional units under the low load Valley mode of the end power grid and makes it difficult for the system to adjust peak load.

(6) The external environment of power grid construction is becoming increasingly severe. Land, space and other resources needed for power grid development will be more scarce, and the difficulty of land requisition and demolition for power grid construction will be further increased. Difficulty in site and path selection has become a major factor restricting the development of power network. The project cannot be put into operation on schedule, which brings hidden dangers to the safe and stable operation of power network.

\section{Planning of External Power Receiving}

\subsection{General principles and steps}

The general principles of the external power receiving plan of the receiving-end grid include:

(1) Meet all the needs. Under the guidance of meeting the demand of power growth, the scheme of outof-region power supply should first select the appropriate scale of power supply, optimize the mode of transmission, and precisely lay out the infeed terminal. At the same time, the plan of receiving electricity should also take into account the functions of optimizing the allocation of energy resources, promoting the utilization of new energy resources and adjusting the structure of energy consumption.

(2) Intrinsic safety. The security and stability of grid should be valued, the "three lines of defense" of power system should be strictly guarded, and a reasonable power network security margin should be maintained.

(3) High efficiency and flexibility. We should combine distance with proximity, give overall consideration, fully adapt to the uncertainty of various boundary conditions, and improve the efficiency of resource allocation.

(4) Reasonable price. Full consideration should be given to the actual situation of the planned power network, the relevant projects should be highly operable, and the implementation cost should be within acceptable range.

The overall idea of external power receiving plan mainly includes the following steps:

(1) Determine the boundary conditions;

Combined with the current situation of planning power grid and the supply-demand pattern, the power demand in each planning-level year and the new power supply in the planning area are defined, and the power market space of each level year in the planning period is analyzed. Define the optional power supply base at the sending end, and preliminarily grasp the key data of its supporting power supply composition, power generation utilization hours, power transmission distance, etc.

(2) Draw up power receiving scheme outside the area;

First of all, select the appropriate power receiving scale according to the power market space of the planned power grid. Secondly, combining with the distribution location of the power supply base at the sending end and the scale of the external transmission, draw up different external power transmission schemes, including transmission mode, voltage level, channel capacity and so on. Finally, combining the main grid structure and load distribution at the receiving-end, select the infeed terminal location of AC / DC power receiving channel, and propose a safe and reliable grid integration scheme.

(3) Feasibility study of power receiving scheme;

The feasibility study of the power receiving scheme mainly includes two aspects: one is the feasibility of the receiving-end power system to consume the external power in the planning area; the other is the engineering implementation feasibility of the power receiving scheme. If there is no feasible power receiving scheme, 
for the problems caused by the lack of external power capacity in the receiving-end power system, it is necessary to study the strengthening scheme of receiving power grid or the further optimization of transmission scheme; for the feasibility of project implementation, it is necessary to study the optimization of engineering technical scheme.

(4) Comprehensive comparison and selection of feasible power receiving schemes;

For several feasible power receiving schemes, the advantages and disadvantages of each scheme are further analyzed through comprehensive technical and economic comparison, and the final recommended scheme is formed by integrating various evaluation indexes.

\subsection{Draft of external power receiving scheme}

\subsubsection{Draw up appropriate power receiving scale}

It is the core problem to select the appropriate power receiving scale for the planning of external power receiving. Usually, according to the planning power market space and considering the uncertainty of the new generation in the area, the power receiving scales of multiple levels will be proposed for research. The reasonable power receiving scale not only depends on the existence of feasible transmission schemes, but also on the comprehensive comparison and selection through economy, safety, reliability, environmental friendliness and other aspects.

\subsubsection{Draw up appropriate transmission scheme}

When drawing up the transmission scheme, various transmission modes, transmission voltage levels and transmission channel capacity should be fully considered in combination with the specific power supply layout at the sending end.

From the perspective of transmission mode, there are mainly $\mathrm{AC}$ transmission and $\mathrm{DC}$ transmission. In addition to the function of power transmission, AC transmission also has the function of network construction. DC transmission is point-to-point transmission with the advantages of large transmission capacity, long distance and low loss. The power receiving scheme should follow the principle that $\mathrm{AC}$ and DC power transmission complement each other and develop together. The proportion of AC and DC power receiving should be reasonably allocated to give full play to the advantages of the two transmission modes.

The transmission voltage level and channel capacity can be compared and analyzed based on the boundary conditions such as the power transmission scale and transmission distance at the sending end, combined with the project investment, transmission economy, equipment manufacturing capacity, project operation experience and other factors.

\subsubsection{Select the appropriate infeed terminal location and grid integration scheme}

The infeed terminal of the external power receiving channel in the receiving power grid is usually $\mathrm{AC} / \mathrm{DC}$ substation/converter station, which has the characteristics of large scale and wide power supply range. Defining the power supply scope and the function positioning in the planning grid structure is very important to select the infeed terminal location. The selection of the infeed terminal location should ensure that it matches with the power evacuation and consumption capacity of the receiving-end grid, and the local consumption of the load center at the receiving-end should be given priority. The infeed terminal location of AC and DC should avoid overlapping of power supply scope as far as possible to ensure reasonable evacuation of power flow under normal mode and mutual support under fault mode. For the receiving-end power grid with multiple DC infeed, the influence of multiple HVDC circuits and AC/DC interaction should be fully considered. In addition, the selection of infeed terminal location should also give full consideration to the difficulty of project implementation, and comprehensively consider the site conditions, investment benefits and other factors.

\subsection{Feasibility study on external power receiving scheme}

\subsubsection{Feasibility study on external power consumption}

The feasibility of external power consumption mainly includes the adaptability, security and stability regulation ability of the receiving-end power grid. The adaptability of power grid regulation capacity mainly combines with the characteristics of power transmission outside the area, and calculates and checks the capacity of peak regulation, frequency regulation and voltage regulation of receivingend system. The security and stability adaptability of power grid is mainly combined with the receiving-end drop point and its grid integration scheme to calculate and check the power flow distribution and voltage stability of the receiving-end power grid.

For the receiving power grid studied, it is necessary to fully consider all kinds of uncertain factors existing in the power grid planning, select representative typical operation modes, and comprehensively analyze the possible adverse effects of external power consumption on the receiving-end power grid.

\subsubsection{Feasibility study on project implementation}

For the proposed external power receiving scheme, the feasibility of the scheme implementation should be comprehensively analyzed from the perspective of the implementation of the supporting power supply at the transmission end, the corridor resources of the transmission channel, the location of the receiving $\mathrm{AC} / \mathrm{DC}$ infeed terminal, and the supporting resources of the receiving-end for the sending channel corridor. 


\subsection{Comprehensive evaluation and comparison of external power receiving schemes}

For the feasible power receiving schemes, a comprehensive comparison can be carried out by calculating various evaluation indexes. Economic and environmental friendliness are two categories of indicators that are usually considered for comprehensive assessment in actual planning.

The main indicators in economic evaluation include:

(1) The investment cost, including the project investment to the receiving substation/converter station, which can be estimated by reference to the cost of the same kind of project in accordance with the design control index of the quota for power network projects. The evaluation indicator can be the cost per kilowatt.

(2) Annual expenses, including the depreciation of fixed assets, the cost of operation and maintenance, and the cost of energy consumption. The evaluation indicator can be cost per kilowatt hour.

Economic comparison generally does not include the common parts of the various programs, but only makes a comparative analysis of the different parts among the schemes.

The main indicators in the assessment of environmental friendliness include:

(1) Power structure, including indicators such as the electricity of clean energy, renewable energy and nonwater renewable energy.

(2) Emission indicators, including the discharge of gaseous pollutants such as $\mathrm{CO}_{2}, \mathrm{SO}_{2}$, NOx and fly ash.

(3) Environmental cost, which refers to the cost of reducing the quality of environmental service functions due to environmental pollution caused by powerreceiving schemes. It includes all the expenses needed to solve environmental pollution and ecological damage from the exploitation, production, transportation, use and recycling of resources to treatment.

\section{Case Analysis}

This section will take a provincial power grid as an example to carry out the planning of external power receiving, and put forward feasible power receiving schemes. At the same time, the technical and economic comparison of each scheme will be carried out, and the comprehensive judgment will be combined with various indicators to form the recommended external power receiving scheme.

\subsection{Power market analysis}

Combined with the current situation of planning power grid and the supply-demand pattern, the power demand in 2025, 2030 and saturation year is shown in Table 1. Looking forward to the future saturated year, new local coal and electricity will be strictly controlled, there is no alternative local power supply except for nuclear power planning; neighbouring provinces have space for further construction of about 7.3 million kilowatt thermal power units, considering the integration of network by 500 kilovolt point. Considering the uncertainty of nuclear power projects, there is still power market space of about 21-29 million $\mathrm{kW}$ in saturated year.

Table 1 Power market analysis

Unit:MW

\begin{tabular}{|r|c|c|c|c|}
\hline \multicolumn{2}{|c|}{ Year } & 2025 & 2030 & $\begin{array}{c}\text { Saturation } \\
\text { year }\end{array}$ \\
\hline \multirow{2}{*}{$\begin{array}{c}\text { Required } \\
\text { Capacity }\end{array}$} & Load & 60000 & 69000 & 80000 \\
\cline { 2 - 5 } & Spare & 7200 & 8280 & 9600 \\
\cline { 2 - 5 } & Total & 67200 & 77280 & 89600 \\
\hline \multicolumn{2}{|r|}{$\begin{array}{c}\text { Provincial Installed } \\
\text { Capacity }\end{array}$} & 54274 & 54274 & 54274 \\
\hline \multicolumn{2}{|c|}{ Available Capacity } & 31454 & 31454 & 31454 \\
\hline \multicolumn{2}{|r|}{ Blocked Capacity } & 22820 & 22820 & 22820 \\
\hline \multirow{2}{*}{$\begin{array}{c}\text { External } \\
\text { Power }\end{array}$} & UHVAC & 6000 & 6000 & 6000 \\
\cline { 2 - 5 } & $500 k V$ AC & 11990 & 11990 & 11990 \\
\hline \multicolumn{2}{|c|}{ Power Market Space } & -17756 & -27836 & -40156 \\
\hline
\end{tabular}

\subsection{Draft external power receiving scheme}

Combined with the power market space, the power supply scale should be within the range of 21-29 million $\mathrm{kW}$. After considering the different $\mathrm{AC} / \mathrm{DC}$ ratios of external power receiving, the following three schemes are preliminarily drawn up. The new added UHVAC lines will further strengthen the regional UHVAC grid, and the wind power and coal power near the area will be sent to this power grid. The new UHVDC lines are point-to-point transmission, which bundles the wind power and coal power far from this area and transmits it to this power grid. The capacity, new station number and transmission line length to be built of the three schemes are shown in Table 2.

Table 2 Three external power receiving schemes

\begin{tabular}{|c|c|c|c|c|}
\hline \multicolumn{2}{|r|}{ Scheme } & 1 & 2 & 3 \\
\hline \multirow{3}{*}{$\begin{array}{c}\text { UHVA } \\
\text { C }\end{array}$} & Capacity(MW) & 13000 & 6000 & 5000 \\
\hline & Substation & 4 & 2 & 2 \\
\hline & Transmission(km) & 1500 & 300 & 300 \\
\hline \multirow{3}{*}{$\begin{array}{c}\text { UHVD } \\
\text { C }\end{array}$} & Capacity(MW) & 8000 & 16000 & 24000 \\
\hline & Converter station & 2 & 4 & 6 \\
\hline & Transmission(km) & 1100 & 2500 & 5500 \\
\hline \multicolumn{2}{|c|}{ Total capacity(MW) } & 21000 & 22000 & 29000 \\
\hline
\end{tabular}

As for the locations of UHVAC and UHVDC infeed terminal, according to the power shortage, UHVDC is first arranged to infeed into the load center with the most serious power shortage. And the overlapping of AC/DC infeed terminals' power supply scope should be avoided as far as possible to ensure the reasonable evacuation of power flow under normal mode and the mutual support of AC and DC under fault mode. Taking scheme 2 as an example, the two DC infeed terminals are selected in two cities, one in the south and the other in the north. 


\subsection{Technical feasibility analysis}

The technical feasibility analysis of the external power receiving schemes mainly includes the following aspects:

(1) MIESCR (Multi-Infeed Effective Short Circuit Ratio). MIESCR can be used to evaluate the support capability of AC system to DC system and the degree of interaction between AC and DC in multi-infeed HVDC system. And the MIESCR of three schemes all exceed 3, which mean the system is strong enough.

(2) Frequency stability check. According to the calculation, the frequency stability of the power grid can be maintained if any DC bipolar blocking occurs under the three schemes. Taking scheme 2 as an example, when one of the 8 MW DC bipolar blocks is blocked, the system frequency drops to $49.65 \mathrm{~Hz}$ at the lowest level, and then quickly recovers to stability.

(3) Voltage stability check. The voltage stability of power grid is checked under four kinds of faults: DC single and double pole blocking fault; near area UHV lines n-1 / $\mathrm{n}-2$ fault; converter station outgoing lines n-1 / $\mathrm{n}-2$ fault; important transmission cross-sections n-1/n-2 fault. And three schemes are all qualified.

(4) Peak shaving ability check. The power receiving scale of the three schemes is relatively large, and the proportion of new energy in the newly added power is relatively high, resulting in peak shaving capacity of the three schemes is insufficient in the "14th five year plan" and in the medium and long term.

\subsection{Comprehensive evaluation of schemes}

\subsubsection{Economic evaluation}

Table 3 below shows the economic evaluation indicators of the three schemes.

Table 3 Economic evaluation indicators

Unit: billion yuan

\begin{tabular}{|c|c|c|c|}
\hline Scheme & 1 & 2 & 3 \\
\hline Capacity(MW) & 21000 & 22000 & 29000 \\
\hline $\begin{array}{c}\text { Investment cost of } \\
\text { power supply }\end{array}$ & 94.3 & 98.7 & 130 \\
\hline $\begin{array}{c}\text { Investment cost of } \\
\text { Transmission }\end{array}$ & 46.3 & 47.5 & 77.5 \\
\hline Total investment cost & 140.6 & 146.2 & 207.6 \\
\hline $\begin{array}{c}\text { cost per } \\
\text { kilowatt(yuan) }\end{array}$ & 6698 & 6647 & 7158 \\
\hline $\begin{array}{c}\text { AC / DC + nuclear } \\
\text { power (billion kWh) }\end{array}$ & 168.5 & 180.5 & 164 \\
\hline Annual expenses & 30.6 & 31.5 & 25.9 \\
\hline $\begin{array}{c}\text { cost per kilowatt } \\
\text { hour(yuan) }\end{array}$ & 0.182 & 0.175 & 0.158 \\
\hline
\end{tabular}

Since the new nuclear power stations in the province are considered in scheme 1 and 2, but not in scheme 3, the cost of nuclear power station is also included in the calculation of the cost of scheme 1 and scheme 2 . It can be seen that the investment cost per kilowatt of scheme 3 is the highest and the cost per kilowatt hour is lower than other schemes.

\subsubsection{Environmental evaluation}

Table 4 below shows the environmental evaluation indicators of the three schemes. The environmental cost includes the environmental cost of all air pollutants discharged in the process of thermal power generation. It can be seen that the proportion of clean energy in scheme 3 is the lowest, and the environmental cost per kilowatt hour is also the highest.

Table 4 Environmental evaluation indicators

Unit: billion $\mathrm{kWh}$

\begin{tabular}{|c|c|c|c|}
\hline Scheme & 1 & 2 & 3 \\
\hline Total electricity & 380 & 380 & 380 \\
\hline $\begin{array}{c}\text { Total clean } \\
\text { electricity }\end{array}$ & 144.2 & 140.5 & 95.4 \\
\hline Proportion & $37.9 \%$ & $37.0 \%$ & $25.1 \%$ \\
\hline Coal electricity & 231.1 & 234.8 & 279.9 \\
\hline Proportion & $60.8 \%$ & $61.8 \%$ & $73.7 \%$ \\
\hline $\begin{array}{c}\text { Environmental } \\
\text { cost(billion yuan) }\end{array}$ & 28.5 & 28.9 & 34.5 \\
\hline $\begin{array}{c}\text { Environmental cost } \\
\text { per kilowatt hour } \\
\text { (yuan) }\end{array}$ & 0.168 & 0.160 & 0.210 \\
\hline
\end{tabular}

\subsubsection{Comprehensive evaluation of schemes}

Table 5 below shows the evaluation indicators of the three schemes.

Table 5 Evaluation indicators

Unit: billion yuan

\begin{tabular}{|c|c|c|c|}
\hline Scheme & 1 & 2 & 3 \\
\hline $\begin{array}{c}\text { Technical } \\
\text { feasibility }\end{array}$ & \multicolumn{2}{|c|}{$\begin{array}{c}\text { The stability and safety of the three schemes } \\
\text { are all qualified. With the increase of DC } \\
\text { capacity, the stability of the scheme decreases } \\
\text { gradually }\end{array}$} \\
\hline $\begin{array}{c}\text { Total investment } \\
\text { cost }\end{array}$ & 140.6 & 146.2 & 207.6 \\
\hline $\begin{array}{c}\text { cost per } \\
\text { kilowatt(yuan) }\end{array}$ & 6698 & 6647 & 7158 \\
\hline $\begin{array}{c}\text { Proportion of clean } \\
\text { electricity }\end{array}$ & $37.9 \%$ & $37.0 \%$ & $25.1 \%$ \\
\hline Environmental cost & 28.5 & 28.9 & 34.5 \\
\hline Annual expenses & 30.6 & 31.5 & 25.9 \\
\hline $\begin{array}{c}\text { cost per kilowatt } \\
\text { hour considering } \\
\text { environmental cost } \\
\text { (yuan) }\end{array}$ & 0.351 & 0.335 & 0.368 \\
\hline
\end{tabular}

The stability and safety of the three schemes are all qualified. With the increase of DC capacity, the stability of the scheme decreases gradually. Then, the investment cost per kilowatt hour and the cost per kilowatt hour after considering the environmental cost of the three schemes are compared. The unit investment and operation cost of scheme 2 are the lowest. Therefore, the final recommended scheme is scheme 2 .

\section{Conclusion}

In view of the background that the proportion of external receiving power is gradually increasing and UHVAC/DC transmission is getting developed, this paper puts forward the scientific planning and comprehensive evaluation scheme of the external power receiving. 
Taking a typical recipient power network in China as example, this paper analysed the reasonable three schemes of power receiving, and conducts comprehensive technical and economic comparisons among various feasible external power receiving schemes. Finally, the recommended scheme is obtained by comparing the investment and operation costs of the three schemes. The planning trains and methods presented in this paper will provide guidance and reference for regional backbone grid planning and receiving-end grid planning.

\section{References}

1. Yu Zhen, Zhao Kezheng, Yu Dunyao. The necessity of interregional interconnected power system in viewing of developing East China power system [J]. Power System Technology, 1995. 19(8) :24-28. 33.

2. Sun Jianping, Miao Qijian. Status quo of crossregional electricity acceptance of East China Power Grid [J]. East China Electric Power, 2007, 35(5): 106-108.

3. Li Mingjie. Characteristic Analysis and Operational Control of Large-Scale Hybrid UHV AC/DC Power Grids [J]. Power grid technology, 2016, No.389 (04):10-16.

4. A lex androv G N. Economical Comparison of AC and DC Transmission Lines [J]. High Volt age Engineering, 2008, 34(11):2259-2261.

5. Li Zhaowei, Zhai Haibao, Liu Fusui, et al. Evaluation of DC integration capability of East China receiving-end power grid $[\mathrm{J}]$. Automation of Electric Power Systems, 2016, 40(16):147-152.

6. Yang Huanhuan, Cai Zexiang, Zhu Lin, et al. Reactive power dynamic characteristics of DC system and its influence on transient voltage stability of receiving power grid [J]. Electric Power Automation Equipment, 2017(10):86-92.

7. Liao Minchuan, Cai Guanglin, Zhang Yongjun. Transient Voltage Stability Analysis of Received End Grid for AC/DC Hybrid System [J]. Power System Protection and Control, 2009 (10): 1-4.

8. Lin Weifang, Tang Yong, Guo Xiaojiang. Analysis of influence factors of short circuit ratio of multifeed AC/DC system [J]. Power Network Technology, 2011, 35 (008): 64-68.

9. Chen Bo, Yin Ting, Huang Yichao, et al. Reactive power issues of Shanghai Power Grid under the background of AC-DC electric power from external regions [J]. Power System and Clean Energy, 2015, 31 (4):66-71.

10. Wang Weiyuan, Zhao Nan, Zhang Jiannan, et al. The influence of external electricity on the proportion of high power consumption is caused by the auxiliary services of end-grid $[\mathrm{J}]$. China Electric Power, 2018 (11): 67-73. 